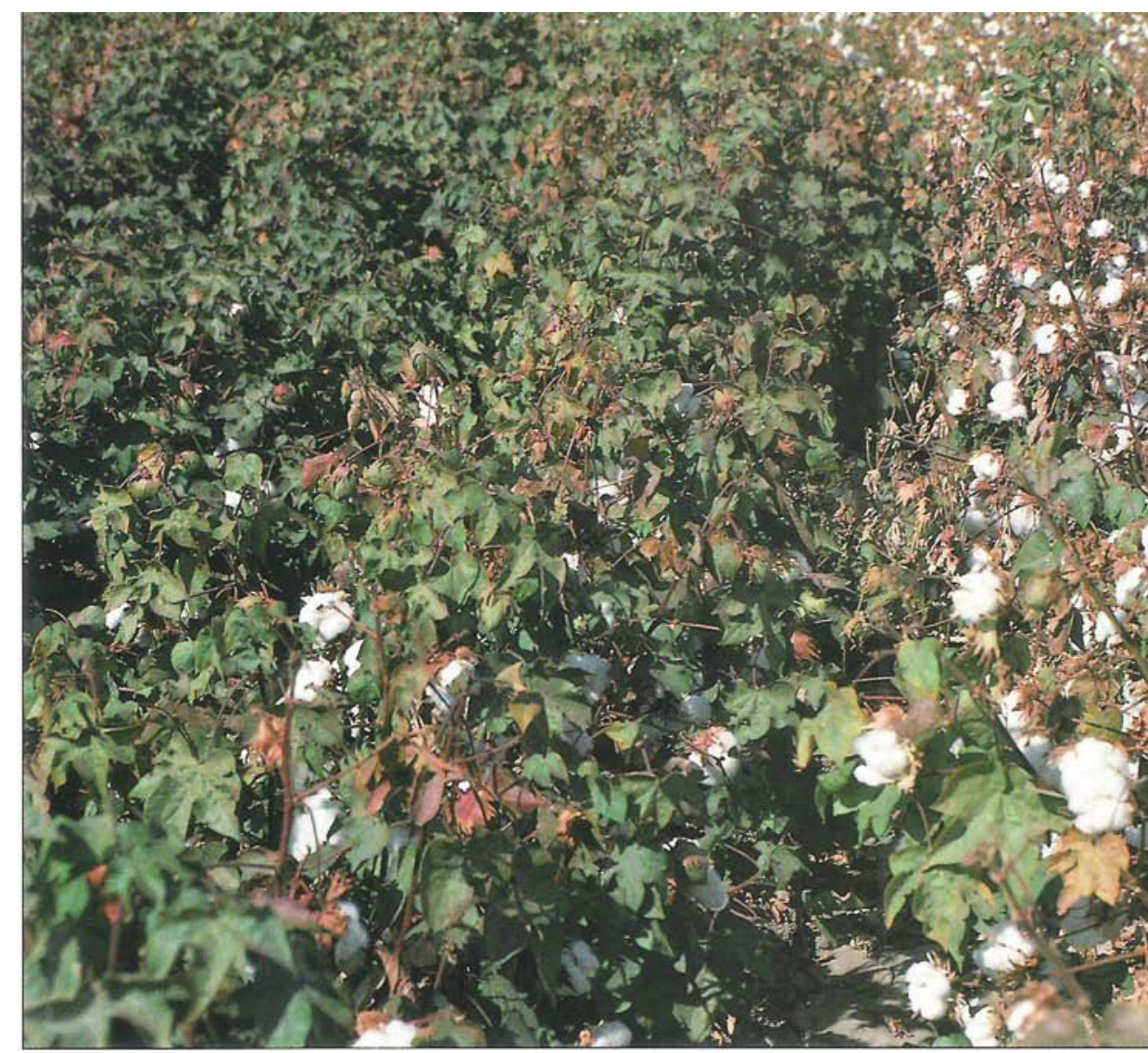

In fumigating Verticillium-infested soils...

\title{
Potassium deficiencies in cotton go down, yields go up
}

\author{
Bill L. Weir \\ 口 James E. DeVay \\ ป

\section{R. Joe Wakeman}

\begin{abstract}
Potassium deficiency symptoms occur on Acala SJ-2 cotton when the soils, by test, are not deficient and when other crops grow well without additions of potassium. Field experiments in 1988, 1989 and 1990 resulted in significant lint yield increases when the soils were fumigated with methyl bromide and chloropicrin. Foliar potassium deficiency symptoms were drastically decreased without altering soil potassium levels.
\end{abstract}

Potassium deficiency symptoms appear on about $20 \%$ to $25 \%$ of San Joaquin Valley cotton in late July and August. Such deficiency symptoms can occur on Acala SJ-2 cotton when the soils, by test, are not deficient and when other crops grow well without additions of potassium. The problem is most severe on soils with high levels of Verticillium wilt and among cotton varieties most susceptible to wilt injury. The symptoms are similar to classical potassium deficiency except that they mainly occur on the top one third of the plant and often develop late in the season.

The earliest symptoms occur when the leaf petiole potassium level is about $1.5 \%$ of the dry weight. At this level the normally soft and pliable leaves become thick, leathery and brittle. The upper surface of the leaves becomes shiny and slight interveinal chlorosis is evident.

As potassium levels in the petioles decrease, leaves deteriorate rapidly. Leaf edges curl and become bronze, then yellow, followed by drying and severe interveinal chlorosis. Eventually, necrotic areas develop between the veins. When potassium levels approach $0.2 \%$, leaf death and abscission follow. In extreme cases, the plant's main stem may become weak and brittle, causing it to lodge. Lint yields of affected plants can be greatly reduced.

The authors, and other researchers, reported (California Agriculture, SeptemberOctober 1986 and May-June 1989) that po-

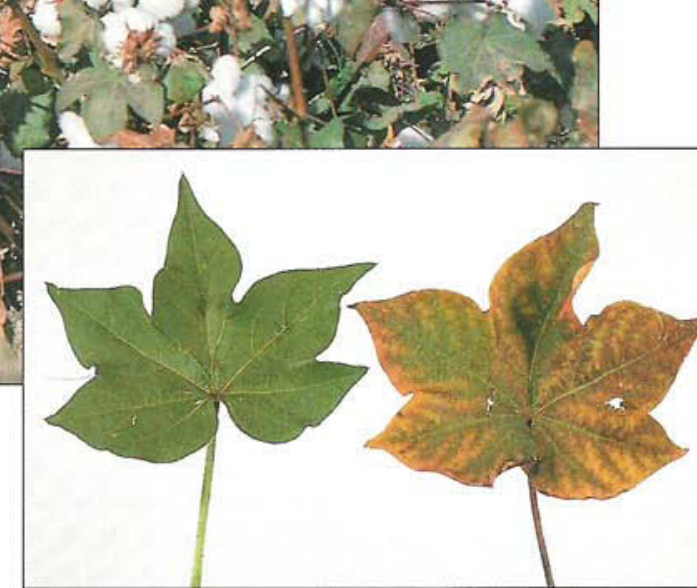

Cotton fields fumigated with methyl bromide were characterized by large green cotton plants (top left) compared to nonfumigated fields (top right). Inset shows green leaf from fumigated field, which produced twice as much cotton lint in 2 of 3 years.

tassium deficiency symptoms occur despite seemingly adequate soil levels. Responses to potassium fertilization were found in tests where Verticillium wilt was high or soil potassium was low. In the 1987 Beltwide Cotton Proceedings, D. Mikkelsen cites evidence suggesting that the potassium deficiency in California cotton is disease induced. His work included field and greenhouse experiments involving radioactive rubidium and scanning electron microscope examinations to show plugging of the vascular system of diseased plants. The authors, with R. Garber and J. Stapleton, reported on the effects of soil solarization on the control of potassium deficiency in California Agriculture, May-June 1989. Lint yields were significantly increased and vascular and foliar symptoms significantly decreased due to soil solarization.

\section{Methods and materials}

Soil fumigation tests were conducted in 1988, 1989 and 1990. The plots were located in Merced County on Crivelli Farms in 1988 and 1989, and on Santa Rita Ranch 
TABLE 1. Effect of soil fumigation on levels of nitrogen, phosphorus and potassium, at two sampling depths in 1990

\begin{tabular}{|c|c|c|c|c|c|c|}
\hline & \multicolumn{2}{|c|}{$\mathrm{N}$} & \multicolumn{2}{|c|}{$P$} & \multicolumn{2}{|c|}{$\mathrm{K}$} \\
\hline & \multicolumn{2}{|c|}{ ppm } & \multicolumn{2}{|c|}{ ppm } & \multicolumn{2}{|c|}{$p p m$} \\
\hline & $0-12 "$ & $12-24 "$ & $0-12^{\prime \prime}$ & $12-24 "$ & $0-12 "$ & $12-24^{\prime \prime}$ \\
\hline Fumigated & 30.9 & 28.5 & 24.4 & 20.0 & 94 & 89 \\
\hline Nonfumigated & 67.0 & 29.8 & 19.3 & 18.3 & 105 & 93 \\
\hline $\operatorname{LSD}(.05)$ & ns & ns & ns & ns & ns & ns \\
\hline
\end{tabular}

in 1990. The soil type was temple clay loam, and represents the major cotton soil in the area. All three sites had a history of verticillium wilt and potassium deficiency symptoms. Plots were 22 feet wide and 600 feet long, replicated four times.

In November of 1987, the year before the tests, 600 pounds of a methyl bromidechloropicrin mixture ( $60 \%$ to $40 \%$ ) were shanked 6 inches deep into the soil and covered with polyethylene clear plastic sheeting (one mil thick). The plastic sheeting was removed 24 hours after methyl bromide fumigation and the sites were treated the same as the rest of the field with regard to listing, preirrigation and weed control. The following April, the plots and surrounding field areas were planted to Acala SJ-2 cotton.

Soil samples were collected from the 1990 test before fumigation and again at planting time for laboratory analysis of nitrogen, phosphorus and potassium content. A soil tube was used to take approximately 20 cores from 0 to 12 inches deep in each fumigated and nonfumigated plot. The cores were mixed thoroughly and a subsample taken for laboratory analyses. The sampling procedure was repeated at a soil depth of 12 to 24 inches.

Leaf petiole samples were collected four times during the growing season and analyzed for nitogren, phophorus and potassium. The youngest fully expanded leaf was selected for sampling. Approximately 30 to 40 leaf petioles were collected from each treatment in the four replicates. All analyses were conducted by the Division of Agriculture and Natural Resources Laboratory, UC Davis.

In October of each year, when the crops became mature, 1/1,000 of an acre was hand harvested in each of the fumigated and nonfumigated plots to determine lint yields per acre.

\section{Results}

Soil samples collected from two depths in fumigated and nonfumigated plots did not differ from one another in nitrogen, phosphorus or potassium content (table 1). All three nutrients were at slightly, but not significantly, lower levels in the second foot depth (12 to 24 inches) than in the first foot. Soil disinfestation by soil solarization (conducted in earlier studies) or by chemi- cal fumigation (in these studies) did not appear to change the availability of extractable nitrogen, phosphorus or potassium. Leaf petiole analyses indicated little effect on the uptake of nitrogen or phosphorus, because values of both nutrients were sufficiently high throughout the growing season (table 2). Potassium, however, was significantly higher on three of the four sampling dates in plants grown in the fumigated soil.

Early in the season (June 18), potassium from petioles of plants grown in fumigated soil increased 14\%. By the end of the season (August 19), the difference was $48 \%$. Areas representing $1 / 1,000$ acre were hand harvested from the fumigated plots and untreated control. Means of lint yields for four replications in each of the 3 years were significantly higher in fumigated plots in every comparison (table 3 ). Increases in yields were $58 \%, 26 \%$ and $58 \%$ in 1988, 1989 and 1990, respectively.

TABLE 2. Leaf petiole levels of nitrogen, phosphorus and potassium from cotton grown in fumigated and nonfumigated soils in 1990

\begin{tabular}{|c|c|c|c|}
\hline & $\mathrm{N}$ & $P$ & $\mathrm{~K}$ \\
\hline JUNE 18 & \multicolumn{2}{|c|}{..........ppm ............... } & $\%$ \\
\hline Fumigated & 20,879 & 1,757 & $5.34 \mathrm{a}$ \\
\hline Nonfumigated & 20,247 & 1,507 & $4.59 \mathrm{~b}$ \\
\hline $\operatorname{LSD}(.05)$ & ns & ns & 0.58 \\
\hline C V $(\%)$ & & & 5.05 \\
\hline \multicolumn{4}{|l|}{ JULY 10} \\
\hline Fumigated & 13,352 & 2,266 & 4.07 \\
\hline Nonfumigated & 11,309 & 1,949 & 3.82 \\
\hline $\operatorname{LSD}(.05)$ & ns & $\mathrm{ns}$ & ns \\
\hline \multicolumn{4}{|l|}{ JULY 30} \\
\hline Fumigated & 6,725 & 2,040 & $4.06 \mathrm{a}$ \\
\hline Nonfumigated & 7,161 & 1,763 & $2.33 b$ \\
\hline $\operatorname{LSD}(.05)$ & ns & ns & 1.37 \\
\hline C V $(\%)$ & & & 18.45 \\
\hline \multicolumn{4}{|l|}{ AUG 17} \\
\hline Fumigated & 2,646 & 2,040 & $4.06 \mathrm{a}$ \\
\hline Nonfumigated & 2,994 & 1,547 & $0.82 \mathrm{~b}$ \\
\hline LSD $(.05)$ & $\mathrm{ns}$ & ns & 0.22 \\
\hline C V $(\%)$ & & & 8.10 \\
\hline
\end{tabular}

TABLE 3. Lint yields of cotton grown on fumigated and nonfumigated soils

\begin{tabular}{lccc}
\hline & 1988 & 1989 & 1990 \\
\hline Fumigated & $1,182 \mathrm{a}$ & $1,306 \mathrm{a}$ & $1,338 \mathrm{a}$ \\
Nonfumigated & $495 \mathrm{~b}$ & $969 \mathrm{~b}$ & $561 \mathrm{~b}$ \\
LSD $(.05)$ & 195 & 322 & 241 \\
C V $(\%)$ & 7.32 & 8.11 & 10.92 \\
\hline
\end{tabular}

\section{Discussion}

Cotton plants from the control treatment in these tests were typically about 2 feet tall and were severely affected with potassium deficiency symptoms and Verticillium wilt. Plants grown in fumigated soil were 4 to 5 feet tall just before defoliation and had little or no potassium deficiency symptoms or Verticillium wilt. Virtually all leaves were green and healthy.

Potassium nutrition appears to be a limiting factor in obtaining full yield potential of cotton grown on Verticilliuminfested soils. To produce adequate potassium nutrient needs, soil applications of 200 to 250 pounds potassium per acre are required to bring about significant yield increases. Our experimental results strongly suggest that potassium deficiency symptoms in these studies were disease related. Mineral nutrients are supplied to new leaves and stems during plant growth; however, during boll formation and development new physiological sinks develop.

Boll walls contain the highest concentrations of potassium (about $4 \%$ dry weight) of all plant parts. Potassium is withdrawn from the upper leaves and petioles and is translocated via phloem sap to the fruit. This sudden and excessive need of potassium, together with restricted potassium movement in the roots and stems of cotton infected by Verticillium dahliae, is the main cause of the potassium deficiency symptoms. Bed drying between irrigations and layering of potassium in the soil were identical in both fumigated and nonfumigated sites because all the fields were treated in the same manner.

In other studies, inoculation of young healthy cotton plants with white isolates of $V$. dahliae, isolated from potassium-deficient cotton plants, induced symptoms of potassium deficiency. Colonies of white isolates of $V$. dahliae lack black pigmentation and produce few, if any, microsclerotia in contrast to the more common black microsclerotia isolates. They originate as irreversible mutations from black microsclerotial strains and appear to constitute a new pathotype that can induce the potassium deficiency symptoms.

Disinfestation of the soil by fumigation resulted in highly significant lint yield increases and in the absence of potassium deficiency symptoms without altering soil potassium levels.

B. L. Weir is Farm Advisor in Merced County, UC Cooperative Extension; J. E. DeVay is Professor, Plant Pathology, UC Davis, and R. J. Wakeman is Staff Research Associate, Plant Pathology, UC Davis.

The authors are grateful to Tri-Cal Inc. for providing and applying the fumigants. 